\title{
Correlação interobservador das alterações morfológicas das vias biliares em pacientes com esquistossomose mansoni pela colangiorressonância magnética*
}

\author{
Evaluation of morphological changes of the biliary tree by magnetic resonance \\ cholangiography in patients with schistosomiasis mansoni: interobserver agreement \\ Danilo Moulin Sales ${ }^{1}$, José Eduardo Mourão dos Santos ${ }^{2}$, David Carlos Shigueoka ${ }^{3}$, Alberto \\ Ribeiro de Souza Leão ${ }^{1}$, Ramiro Colleoni Neto ${ }^{4}$, Durval Rosa Borges ${ }^{5}$, Giuseppe D'Ippolito ${ }^{6}$, \\ Jacob Szejnfeld ${ }^{6}$
}

Resumo OBJETIVO: Descrever as alterações das vias biliares pela colangiografia por ressonância magnética (CPRM) na esquistossomose hepatoesplênica e avaliar a concordância interobservador da CPRM na detecção de colangiopatia esquistossomótica. MATERIAIS E MÉTODOS: Estudo prospectivo e transversal em 24 pacientes com a forma hepatoesplênica da esquistossomose mansoni e em 6 pacientes sadios, como grupo controle, com avaliação da via biliar pela CPRM. As alterações da via biliar consideradas foram: distorção, afilamento, estenose, dilatação e irregularidade. Foi calculada a concordância interobsevador para alteração da via biliar com o teste de McNemar e o índice kappa $(\kappa)$. RESULTADOS: A concordância interobservador na caracterização de distorção e afilamento da via biliar foi quase perfeita ( $\kappa=0,867$; intervalo de confiança [IC] 95\% [0,512-1,0] e $K=0,865$; IC 95\% [0,51-1,0], respectivamente). A concordância foi substancial para a estenose $(\kappa=0,78$; IC $95 \%[0,424-1,0]$ ), moderada para dilatação ( $\kappa=0,595$; IC 95\% [0,247$0,942]$ ) e regular para afilamento ( $\kappa=0,229$; IC 95\% [0,095-0,552]). CONCLUSÃO: As alterações observadas nas vias biliares foram, em ordem decrescente de ocorrência: distorção, afilamento, estenose, dilatação e irregularidade. A concordância interobservador para sinais de colangiopatia esquistossomótica foi quase perfeita para distorção e afilamento e substancial para estenose.

Unitermos: Esquistossomose mansoni; Imagem por ressonância magnética; Colangiografia; Ductos biliares.

Abstract OBJECTIVE: To describe changes of the biliary tree demonstrated by magnetic resonance cholangiography (MRC) in patients with the hepatosplenic presentation of schistosomiasis mansoni, and evaluating the interobserver agreement in the detection of schistosomal cholangiopathy. MATERIALS AND METHODS: Prospective, cross-sectional study involving 24 patients with hepatosplenic schistosomiasis and 6 healthy patients (control group) submitted to biliary tree evaluation by MRC. The following changes of the biliary tree were considered: distortion, thinning, stenosis, dilation and irregularity. The interobserver agreement in the detection of biliary tree changes was calculated with the McNemar's test and the kappa index of agreement $(\kappa)$. RESULTS: The interobserver agreement in the detection of distortion and thinning of the biliary tree was almost perfect $(\kappa=0.867$; confidence interval $[\mathrm{Cl}] 95 \%[0.512-1.0]$ and $\kappa=0.865 ; \mathrm{Cl} 95 \%$ [0.51-1.0], respectively). There was a substantial agreement for stenosis ( $\mathrm{K}=0.78 ; \mathrm{Cl} 95 \%[0.424-1.0]$ ), moderate agreement for dilation ( $\kappa=0.595 ; \mathrm{Cl} 95 \%$ [0.247-0.942]) and mild agreement for thinning ( $\kappa=$ 0.229; $\mathrm{Cl} 95 \%$ [0.095-0.552]). CONCLUSION: In a decreasing order of frequency, the changes of the biliary tree were observed: distortion, thinning, stenosis, dilation and irregularity. The interobserver agreement for signs of schistosomal cholangiopathy was almost perfect for distortion and thinning, and substantial for stenosis.

Keywords: Schistosomiasis mansoni; Magnetic resonance imaging; Cholangiography; Biliary ducts.

Sales DM, Santos JEM, Shigueoka DC, Leão ARS, Colleoni Neto R, Borges DR, D'lppolito G, Szejnfeld J. Correlação interobservador das alterações morfológicas das vias biliares em pacientes com esquistossomose mansoni pela colangiorressonância magnética. Radiol Bras. 2009;42(5):277-282.

* Trabalho realizado na Universidade Federal de São Paulo/ Escola Paulista de Medicina (Unifesp/EPM), São Paulo, SP, Brasil.

1. Mestres, Médicos Radiologistas da Universidade Federal de São Paulo/Escola Paulista de Medicina (Unifesp/EPM), São Paulo, SP, Brasil.

2. Doutor, Médico Radiologista da Universidade Federal de São Paulo/Escola Paulista de Medicina (Unifesp/EPM), São Paulo, SP, Brasil.
3. Mestre, Médico Radiologista, Professor Afiliado da Universidade Federal de São Paulo/Escola Paulista de Medicina (Unifesp/EPM), São Paulo, SP, Brasil.

4. Doutor, Médico Cirurgião, Professor Afiliado da Universidade Federal de São Paulo/Escola Paulista de Medicina (Unifesp/EPM), São Paulo, SP, Brasil.

5. Livre-docente, Professor Titular do Departamento de Medicina da Universidade Federal de São Paulo/Escola Paulista de Medicina (Unifesp/EPM), São Paulo, SP, Brasil.
6. Livres-docentes, Professores Associados do Departamento de Medicina da Universidade Federal de São Paulo/Escola Paulista de Medicina (Unifesp/EPM), São Paulo, SP, Brasil.

Endereço para correspondência: Dr. Danilo Moulin Sales. Rua das Figueiras, 550, ap. 132, Bairro Jardim. Santo André, SP, Brasil, 09080-300. E-mail: daniloevaleria@uol.com.br

Recebido para publicação em 5/2/2009. Aceito, após revisão, em 11/8/2009. 


\section{INTRODUÇÃO}

A esquistossomose, dentre as doenças parasitárias que assolam o mundo, constitui uma das mais prevalentes, estimando-se em 200 milhões a 300 milhões de pessoas atingidas em mais de 74 países $^{(1-3)}$. No Brasil, a esquistossomose mansoni atinge uma população estimada entre 8 milhões e 18 milhões de indivíduos infectados, distribuídos numa faixa endêmica que se estende do Rio Grande do Norte até Minas Gerais ${ }^{(\mathbf{1 - 1 2})}$.

$\mathrm{Na}$ forma crônica, ao contrário do que se observa em hepatopatias semelhantes, constata-se preservação relativa da função hepática, predominando os sintomas decorrentes de hipertensão portal, caracteristicamente independente da ocorrência de lesão hepatocelular ${ }^{(13)}$. No fígado, o substrato anatômico da doença, que leva à forma letal da esquistossomose mansoni com o quadro de hipertensão portal, é a extensa fibrose dos espaços periportais. Esta fibrose faz parte do processo de cicatrização que segue a reação inflamatória granulomatosa aguda, ao redor dos ovos de Schistosoma aprisionados nos pequenos vasos hepáticos ${ }^{(14-16)}$.

Um aspecto que tem chamado a atenção quanto à patogênese da esquistossomose é o envolvimento secundário da via biliar pelo processo inflamatório periportal ${ }^{(1,11,17)}$.

Os métodos diagnósticos invasivos mais comumente usados para o estudo da árvore biliar são a colangiopancreatografia retrógrada endoscópica (CPRE) e a colangiografia transparieto-hepática (CTPH). Mais recentemente, a colangiopancreatografia por ressonância magnética (CPRM) veio proporcionar imagens colangiográficas semelhantes às da CPRE, sem o inconveniente e as complicações de um procedimento invasivo, e além disso, com a vantagem de se estudar o parênquima hepático, o sistema porta e outras alterações relacionadas à hipertensão portal ${ }^{(18-22)}$.

Assim, as alterações das vias biliares puderam ser acessíveis por um método não invasivo, o que nos motivou buscar um melhor entendimento das alterações das vias biliares nos pacientes esquistossomóticos. Propomos validar o método de imagem, por meio da avaliação da concordância interobservador, e analisar as principais alterações morfológicas percebidas nas vias biliares desses pacientes.
Dessa forma, os objetivos deste trabalho foram os seguintes: 1) descrever as alterações das vias biliares intra e extra-hepáticas na CPRM mais frequentemente observadas na esquistossomose hepatoesplênica; 2) avaliar a concordância interobservador da CPRM na detecção de colangiopatia esquistossomótica.

\section{MATERIAIS E MÉTODOS}

Entre fevereiro de 2005 e fevereiro de 2007, realizamos estudo observacional e transversal em 30 pacientes, 24 deles portadores de esquistossomose mansoni com a forma hepatoesplênica e 6 sadios, tidos como grupo controle, estudados por colangiorressonância magnética. $\mathrm{O}$ estudo foi conduzido no Hospital São Paulo/Universidade Federal de São Paulo (Unifesp), tendo sido aprovado pelo Comitê de Ética em Pesquisa da Unifesp (1667/05) e obtido o consentimento informado de cada paciente. $\mathrm{O}$ grupo estudado foi composto por 17 homens e 13 mulheres, com idade variável entre 23 e 72 anos e média de 40 anos.

\section{Critérios de inclusão}

- Idade acima de 18 anos.

- Pacientes com diagnóstico de esquistossomose: biópsia retal ou forte evidência clínico-laboratorial (coproparasitológico positivo, padrão de fibrose periportal na ultrassonografia) e epidemiológica (contato com rios e lagoas em áreas endêmicas) da doença ${ }^{(21,22)}$.

\section{Critérios de não inclusão}

- Pacientes portadores de outras hepatopatias crônicas associadas, detectadas por exames laboratoriais e investigação epidemiológica nas consultas iniciais.

- Pacientes com contraindicação ao exame de RM (marcapasso cardíaco, implante coclear, claustrofobia, clipe de aneurisma cerebral).

\section{Exames de RM}

Todos os exames foram realizados em equipamento de alto campo operando em 1,5 tesla e gradiente de $40 \mathrm{mT} / \mathrm{m}$ (Magnetom Symphony ${ }^{\mathrm{TM}}$; Siemens Medical Systems, Erlangen, Alemanha), com bobina de sinergia. Foi estabelecido jejum de seis a oito horas antes da realização dos exames.
As sequências de pulso utilizadas estão descritas na Tabela 1.

\section{Padronização da análise dos exames de RM}

Os exames de RM foram interpretados por dois médicos radiologistas, ambos com mais de dez anos de experiência em radiologia do abdome, denominados examinadores 1 e 2. A avaliação dos exames de RM foi efetuada de forma independente e cega. Foram analisadas as sequências de imagem SSTSE e 3D TSE restore em estação de trabalho. Avaliaram-se alterações das vias biliares por meio de critérios estabelecidos previamente, conforme descritos a seguir.

- Estenose: estreitamentos focais do calibre dos ductos (Figura 1).

- Dilatação: aumento do calibre ductal quando comparado com segmentos adjacentes do mesmo nível (Figura 1).

- Afilamento: estreitamento ou alongamento difuso de um ducto biliar (Figuras 2 e 3).

- Irregularidade: presença de saliências ou reentrâncias nas paredes dos ductos ( $\mathrm{Fi}$ gura 3 ).

- Distorção e/ou desarranjo: desvio irregular dos trajetos dos ductos ou distribuição desarmônica dos mesmos (Figuras 3 e 4).

\section{Análise estatística}

A concordância entre os observadores foi avaliada pelo teste McNemar e foram também calculados os índices kappa $(\kappa)$ e o respectivo intervalo de confiança de $95 \%$ (IC 95\%). Para o valor de $\kappa$ foi adotada a categorização de acordo com Landis e Koch. A associação entre alteração da via biliar e gama glutamil transferase (GGT) foi avaliada com o teste exato de Fisher. Os valores de $p<0,05$ foram considerados estatisticamente significantes.

\section{RESULTADOS}

\section{Avaliação da concordância interobservador nas alterações das vias biliares observadas na CPRM}

$\mathrm{Na}$ avaliação das alterações das vias biliares do grupo de pacientes portadores de esquistossomose mansoni, o examinador 1 encontrou distorção em $62 \%$, estenose e irregularidade em $41 \%$, dilatação em $29 \%$ e afilamento em $58 \%$ dos pacientes. Este examinador ainda relatou afilamento 
Tabela 1 Parâmetros técnicos utilizados nas sequências de rotina.

\begin{tabular}{|c|c|c|c|c|c|c|c|}
\hline Sequência & $\begin{array}{l}\text { FLASH - em fase } \\
\text { e fora de fase }\end{array}$ & T2 TSE & T2* GRE (FISP) & T2 HASTE & $\begin{array}{l}\text { 3D VIBE pré- e } \\
\text { pós-contraste }\end{array}$ & SSTSE & 3D TSE restore \\
\hline $\mathrm{TR}(\mathrm{ms})$ & 173 & 1.670 & 20 & 900 & 5,45 & 4.500 & 1.500 \\
\hline $\mathrm{TE}(\mathrm{ms})$ & $2,38 / 5,0$ & $86 / 173$ & $4 / 9$ & 87 & 2,59 & 992 & 681 \\
\hline Ângulo de inclinação $\left({ }^{\circ}\right)$ & 70 & 90 & 20 & 180 & 30 & 150 & 170 \\
\hline Número de excitações & 1 & 2 & - & 1 & 1 & 1 & 1 \\
\hline $2 \mathrm{D} / 3 \mathrm{D}$ & $2 \mathrm{D}$ & $2 \mathrm{D}$ & $2 \mathrm{D}$ & $2 \mathrm{D}$ & $3 \mathrm{D}$ & $2 \mathrm{D}$ & $3 \mathrm{D}$ \\
\hline Espessura (mm) & 8 & 8 & 8 & 5 & 2,5 & 40 & 1,5 \\
\hline Espaçamento & 2 & 0,8 & 0,8 & 0,5 & 0 & 0 & 0,75 \\
\hline Campo de visão & 350 & 350 & 350 & 350 & 350 & 350 & 380 \\
\hline Número de cortes & 30 & 30 & 30 & 30 & 1 & 1 & 40 \\
\hline Orientação & Axial & Axial & Axial & Coronal & Volumétrico & Coronal & Coronal \\
\hline Tempo de aquisição (s) & 48 & 194 & - & 27 & 20 & 4,5 & 1,32 \\
\hline Fase/frequência & $134 / 256$ & $144 / 320$ & - & $195 / 256$ & $134 / 256$ & $410 / 512$ & $384 / 384$ \\
\hline Campo de visão retangular & $75 \%$ & $75 \%$ & - & Não & $75 \%$ & Não & Não \\
\hline Saturação de gordura & Não & Sim & Não & Não & Sim & Sim & Não \\
\hline Pré-saturação & Não & Não & Não & Não & Não & Não & Não \\
\hline Fourier parcial & Não & Não & Não & Sim & Não & Sim & Não \\
\hline Bobina & $\begin{array}{c}\text { Torso em arranjo } \\
\text { de fase }\end{array}$ & $\begin{array}{c}\text { Torso em arranjo } \\
\text { de fase }\end{array}$ & $\begin{array}{c}\text { Torso em arranjo } \\
\text { de fase }\end{array}$ & $\begin{array}{c}\text { Torso em arranjo } \\
\text { de fase }\end{array}$ & $\begin{array}{c}\text { Torso em arranjo } \\
\text { de fase }\end{array}$ & $\begin{array}{c}\text { Torso em arranjo } \\
\text { de fase }\end{array}$ & $\begin{array}{c}\text { Torso em arranjo } \\
\text { de fase }\end{array}$ \\
\hline Número de medidas/repetições & 2 & 4 & - & 1 & 1 & 1 & 1 \\
\hline Circuito de disparo por ECG & Não & Não & Não & Não & Não & Não & Não \\
\hline Compensação respiratória & Não & Sim & Não & Não & Não & Não & Sim \\
\hline Ordem (cobertura do espaço K) & Padrão & Padrão & Padrão & Half-Fourier & - & Half-Fourier & Padrão \\
\hline Disparo & Múltiplo & Múltiplo & Múltiplo & Múltiplo & Múltiplo & Simples & Múltiplo \\
\hline Comprimento do trem de eco & Fast & 11 & - & 195 & Fast & 410 & 129 \\
\hline Largura de banda (Hz/pixel) & 380 & 252 & - & 391 & 250 & 140 & 250 \\
\hline Apneia & Sim & Não & Não & Sim & Sim & Sim & Não \\
\hline
\end{tabular}

FLASH, fast low angle shot; TSE, turbo spin eco; GRE, gradiente-eco; FISP, fast imaging with steady state precession; HASTE, half-Fourier single shot turbo spin echo; VIBE, volume interpolated breath hold examination; SSTSE, single shot turbo spin eco; TR, tempo de repetição; TE, tempo de eco; ECG, eletrocardiograma.
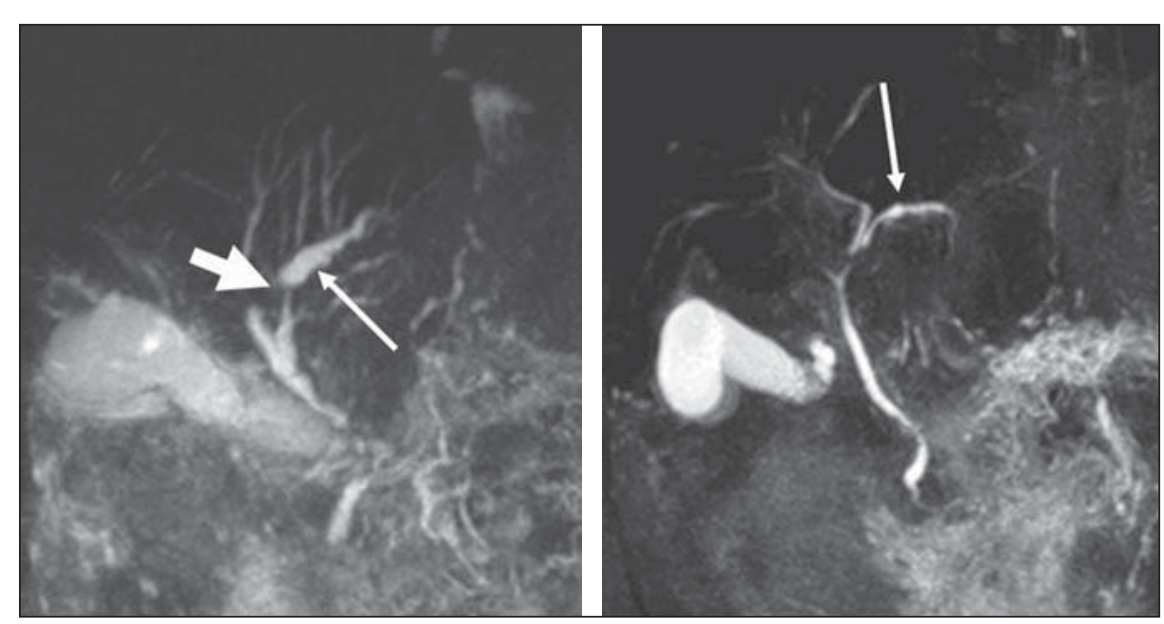

Figura 1. Alterações observadas das vias biliares. Estenose (seta curta) e dilatação (setas longas).

de ductos biliares em um dos pacientes sadios, pertencente ao grupo controle.

Quanto às alterações das vias biliares do grupo de pacientes esquistossomóticos, o examinador 2 encontrou distorção em 54\%, estenose em $45 \%$, dilatação em $41 \%$, irregularidade em $20 \%$ e afilamento em $50 \%$ dos pacientes. Este examinador não encontrou alterações nas vias biliares dos pacientes do grupo controle.
Na caracterização de afilamento e de distorção da via biliar pela CPRM, houve concordância quase perfeita entre os observadores $(\kappa=0,865$; IC $95 \%[0,51-1,0]$ e $\kappa$ $=0,867$; IC $95 \%[0,512-1,0]$, respectivamente).

Houve concordância substancial entre os observadores quanto à caracterização de estenose da via biliar pela CPRM $(\kappa=0,78$; IC 95\% [0,424-1,0]).

Quanto à caracterização de dilatação da via biliar pela CPRM, houve concordância moderada entre os observadores $(\kappa=0,595$; IC 95\% [0,247-0,942]) e concordância regular quanto à caracterização de irregularidade da via biliar $(\kappa=0,229$; IC $95 \%$ [0,095-0,552]).

De modo geral, considerando-se a presença ou ausência de qualquer tipo de alteração na árvore biliar, a concordância entre os examinadores foi substancial $(\kappa=$ 0,722; IC 95\% [0,364-1,0]). 


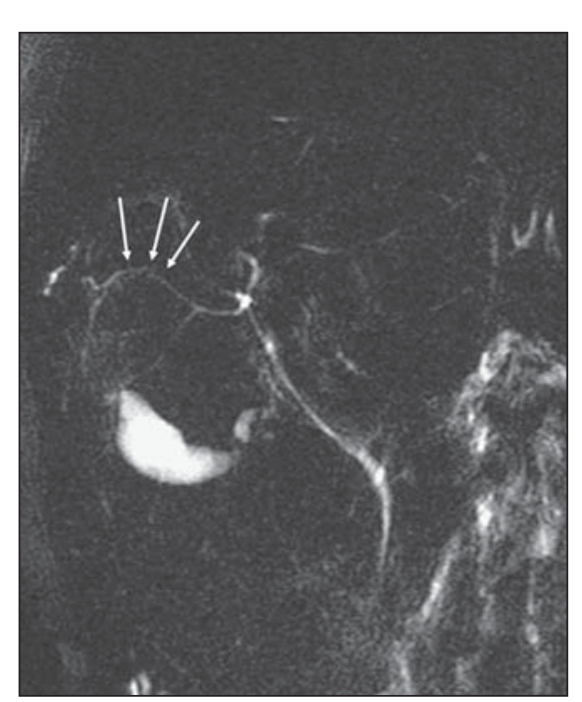

Figura 2. Alterações obsenvadas das vias biliares. Afilamento.

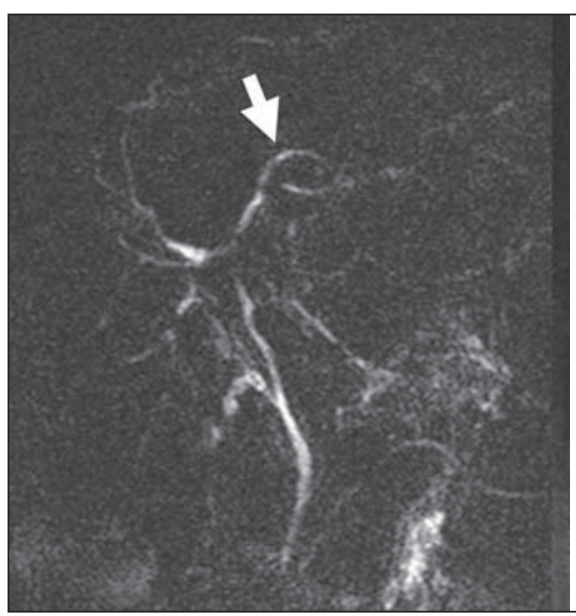

Figura 3. Alterações observadas das vias biliares. Irregularidade (seta curta), afilamento e distorção de ductos de segunda ordem (setas longas).

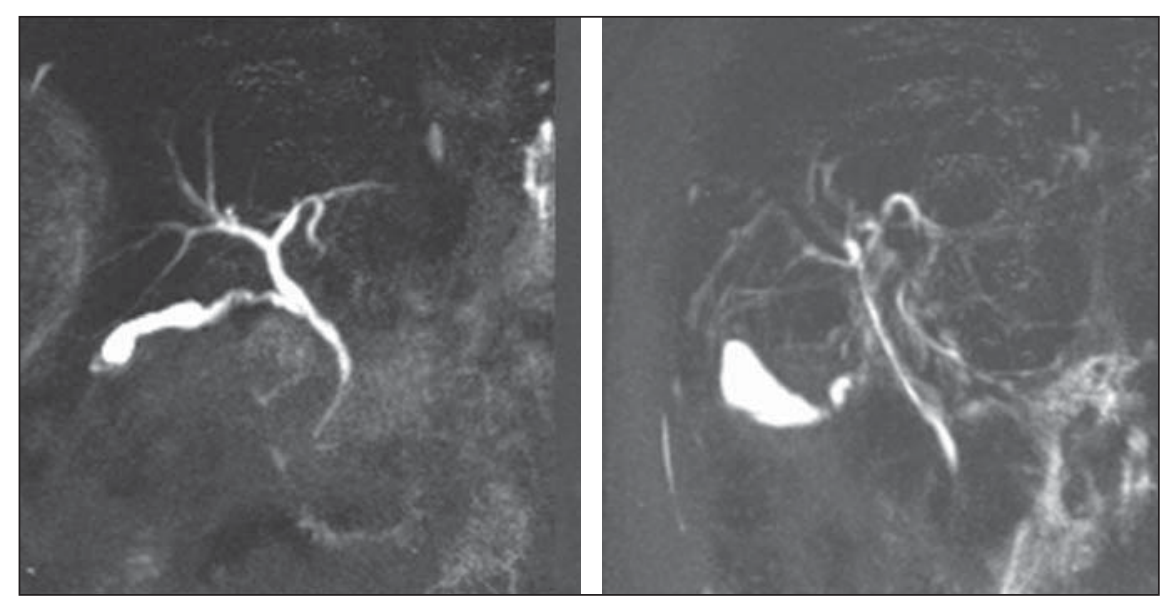

Figura 4. Alterações observadas das vias biliares. Árvore biliar considerada harmônica (à esquerda) e com distorção (à direita), pela sequência SSTSE.

\section{Correlação entre a presença de alteração na via biliar pela CPRM e a GGT sérica}

$\mathrm{Na}$ Tabela 2 demonstramos a correlação entre a presença de alteração na via biliar com a ocorrência de elevação da GGT, utilizando para isso a leitura do examinador 2. O valor de $p$ encontrado foi de 0,471 , não sendo significante.

Tabela 2 Correlação entre a alteração da via biliar e a GGT sérica.

\begin{tabular}{cccc}
\hline \multirow{2}{*}{$\begin{array}{c}\text { Alteração } \\
\text { da via biliar }\end{array}$} & Normal & Elevada & Total \\
\cline { 2 - 4 } Não & 0 & 2 & 2 \\
Sim & 9 & 7 & 16 \\
Total & 9 & 9 & 18 \\
\hline
\end{tabular}

GGT, gama glutamil transferase.

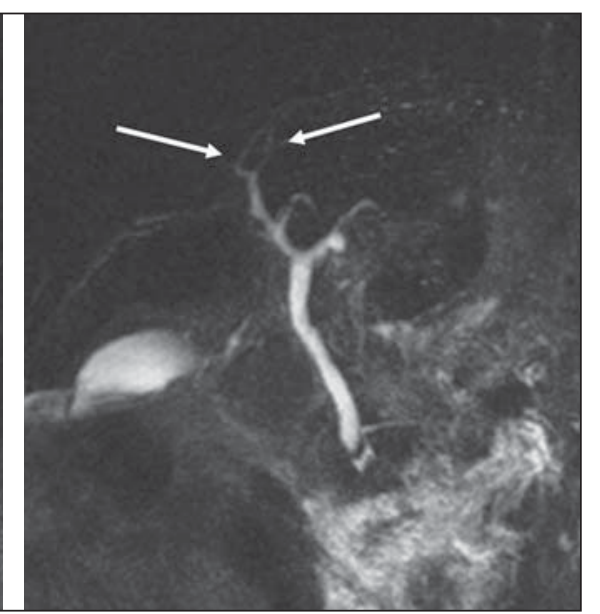

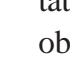
observada tanto na forma hepatoesplênica
quanto na forma hepatointestinal ${ }^{(1)}$ Aparentemente, o mecanismo da elevação da GGT na esquistossomose é distinto daquele da hepatopatia alcoólica. Assim, como observado na cirrose biliar primária, a elevação da GGT na esquistossomose mansoni responde à terapia com o ácido ursodeoxicólico ${ }^{(26)}$.

Em estudo pioneiro com o uso da colangiografia percutânea em pacientes vivos, colangiografia pós-morte e moldes de "vinilite" de fígados normais e com doenças diversas, Ganc observou, nos fígados esquistossomóticos, alterações da árvore biliar intra-hepática com características desarmônicas, distorções ductais, irregularidades das paredes, impressões micronodu- 
lares, estenoses focais curtas e aumento do número de ângulos obtusos de ramos biliares. Além disso, observou um enchimento ductal pobre nas colangiografias pós-morte e rico nas transparieto-hepáticas, inferindo aumento da resistência ou diminuição da complacência das vias biliares/tecido peribiliar nesses pacientes, decorrente do processo fibrótico de base. Notou ainda um paralelismo entre as alterações do sistema portal e as do biliar ${ }^{(25)}$. Esse paralelismo deve-se à alta sensibilidade das vias biliares às alterações inflamatórias de tecidos vizinhos. O processo inicia-se pela formação de granulomas que se desenvolvem a partir de ovos de Schistosoma mansoni depositados no espaço portal. Nessa primeira etapa, o espaço portal encontra-se alargado por edema e um infiltrado celular com predomínio de eosinófilos, linfócitos e macrófagos. Na fase crônica, o espaço portal apresenta-se alargado pela fibrose, além de granulomas periovulares ${ }^{(\mathbf{1 1 , 2 3})}$

Foram descritas alterações de ductos biliares em cobaias submetidas à infecção por Schistosoma mansoni, caracterizadas por graus variáveis de hiperplasia ductal, por vezes com sinais de aumento de secreção mucinosa ${ }^{(\mathbf{1 1}, 23)}$. A fibrose, na fase crônica, determina alterações mecânicas sobre os ductos biliares, relacionadas com as forças compressivas e retráteis características dessa alteração histológica.

Já foi proposto que alterações da árvore biliar secundárias à fibrose periportal da forma crônica da esquistossomose mansoni poderiam servir de base anatômica para o estabelecimento da colestase ${ }^{(\mathbf{1 7 , 2 5 , 2 7 )}}$. Desse modo, levanta-se a possibilidade da correlação do mecanismo de elevação da GGT com a presença de alteração da via biliar observada nesses pacientes.

Sabemos, no entanto, que outras características clínicas da esquistossomose também podem estar relacionadas com as alterações enzimáticas descritas acima. Em um estudo com o uso da ultrassonografia Doppler em pacientes esquistossomóticos, Alves et al. encontraram correlação positiva entre o fluxo sanguíneo na veia porta e os níveis séricos da GGT. Aventaram a hipótese de que a congestão hepática, relacionada com o regime de maior fluxo e pressão no sistema porta, também influenciaria a colestase $^{(3)}$.
Do ponto de vista morfológico das alterações das vias biliares, pode haver uma associação de fatores causais determinantes, por exemplo, a própria fibrose, uma alteração marcante e característica da doença, as alterações microscópicas intrínsecas dos ductos biliares, e ainda, os efeitos mecânicos exercidos pelos vasos portais ectasiados sobre a via biliar adjacente. A possibilidade da causa intrínseca microscópica como um fator determinante na elevação da GGT explicaria, por exemplo, o fato de a elevação dessa enzima preceder as alterações morfológicas macroscópicas observadas pela $\mathrm{CPRE}^{(\mathbf{1 7})}$ ou não se correlacionar diretamente com as alterações ultrassonográficas observadas nesses fíga$\operatorname{dos}^{(1)}$.

Os aspectos clínicos da elevação da GGT na esquistossomose já foram abordados por Brant et al., num outro trabalho, partindo do mesmo projeto de pesquisa que este nosso $^{(\mathbf{1 7})}$.

Diversos trabalhos já estabeleceram a eficácia da CPRM para o estudo das vias biliares, apontando este método diagnóstico como alternativa à CPRE, quando não se vislumbra terapia adjuvante ${ }^{(\mathbf{2 8 , 2 9 )}}$. Porém, não encontramos, na literatura, dados que validassem o uso da CPRM para as alterações das vias biliares observadas na esquistossomose mansoni, ou ainda, que avaliassem a reprodutibilidade do método no estudo desta doença.

Diante da frequência com que ocorrem as alterações das vias biliares nos pacientes esquistossomóticos e da alta prevalência desta doença na nossa população, validado ainda pela presença de um quadro colestático ainda não bem compreendido clinicamente, faz-se necessário o estabelecimento de um método não invasivo, preciso e reprodutível para o estudo da via biliar destes pacientes.

Dessa forma procuramos, neste trabalho, reproduzir as alterações das vias biliares de pacientes esquistossomóticos descritas previamente pela colangiografia convencional, com o uso da CPRM.

Não podemos deixar de considerar o fato de a CPRM apresentar uma menor acurácia, em relação às colangiografias convencionais, para o estudo das vias biliares intra-hepáticas de calibre normal ou reduzido. Sabemos que isto se dá, principal- mente, por causa da sua limitação quanto à resolução espacial e à relação sinal-ruído. Esta limitação prejudicaria especialmente a avaliação de afecções ditas ductopênicas. A introdução de novas tecnologias, como o equipamento de RM com campo magnético de três tesla, veio melhorar esses parâmetros técnicos e, portanto, aventar a possibilidade de aumentar a sua acurácia $^{(30)}$. Outro fator a ser considerado é o fato de a colangiografia convencional e a colangiografia pós-morte (esta realizada no trabalho de Ganc $^{(25)}$ ) trabalharem com a injeção de contraste sob pressão na via biliar, ao contrário da CPRM, que gera imagens da via biliar sob pressão normal.

As alterações morfológicas observadas nesses segmentos da via biliar foram, como já exposto, distorção da árvore biliar, afilamento, estenose, dilatação e irregularidade dos contornos dos ductos.

A concordância entre os observadores na caracterização de distorção da árvore biliar e de afilamento de ductos biliares foi quase perfeita. Quanto à definição de estenose de ductos biliares, a concordância interobservador foi substancial. Por fim, a concordância interobservador foi moderada na visualização de dilatação e regular para irregularidade dos ductos biliares. Não houve correlação entre a presença de alteração da via biliar com a GGT.

As alterações encontradas nas vias biliares dos pacientes esquistossomóticos pela CPRM foram ainda concordantes com aquelas pioneiramente descritas por Ganc, por meio da colangiopancreatografia percutânea e pela colangiografia pós-morte, validando este método para o estudo das vias biliares secundariamente comprometidas pela esquistossomose mansoni.

\section{CONCLUSÕES}

1. As alterações observadas nas vias biliares desses pacientes foram, em ordem decrescente de ocorrência: distorção da árvore biliar, afilamento, estenose, dilatação e irregularidade.

2. A concordância interobservador de sinais de colangiopatia esquistossomótica pela CPRM foi quase perfeita para a caracterização de distorção e afilamento da árvore biliar, e substancial para detecção de estenose. 


\section{REFERÊNCIAS}

1. Amaral AC, Aguiar LA, Souza MR, et al. Serum gamma-glutamyltransferase alteration in hepatic schistosomiasis doesn't correlate with parasitic load and precedes ultrasound alterations. Arq Gastroenterol. 2002;39:27-31.

2. Scortegagna Junior E, Leão ARS, Santos JEM, et al. Avaliação da concordância entre ressonância magnética e ultra-sonografia na classificação da fibrose periportal em esquistossomóticos, segundo a classificação de Niamey. Radiol Bras 2007:40:303-8

3. Alves A Jr, Fontes DA, Melo VA, et al. Schistosomal portal hypertension: influence of the portal blood flow in serum levels of hepatic enzymes. Arq Gastroenterol. 2003;40:203-8.

4. Borges DR. Etiopatogenia das alterações de testes plasmáticos da hemostasia na forma hepatesplênica da esquistossomose mansoni. GED Gastroenterol Endosc Dig. 1995; 14:251-3.

5. Gonzalez TD, Santos JEM, Sales DM, et al. Avaliação ultra-sonográfica de nódulos sideróticos esplênicos em pacientes esquistossomóticos com hipertensão portal. Radiol Bras. 2008;41:69-73.

6. Leão ARS, Santos JEM, Moulin DS, et al. Mensuração do volume de fluxo portal em pacientes esquistossomóticos: avaliação da reprodutibilidade do ultra-som Doppler. Radiol Bras. 2008;41: $305-8$.

7. Oliveira-e-Silva A, D'Albuquerque LA. Hepatosplenic schistosomiasis mansoni: a tragic disease. Arq Gastroenterol. 2003;40:201-2.

8. Santos GT, Sales DM, Leão ARS, et al. Reprodutibilidade da classificação ultra-sonográfica de Niamey na avaliação da fibrose periportal na esquistossomose mansônica. Radiol Bras. 2007;40: 377-81.

9. Costa JD, Leão ARS, Santos JEM, et al. Quantificação do fluxo portal em indivíduos sadios: comparação entre ressonância magnética e ultrasom Doppler. Radiol Bras. 2008;41:219-24.

10. Raia S, Massarollo PCB, Mellendez HEV. Trata- mento cirúrgico da hipertensão portal na esquistossomose mansônica: estado atual da questão. Rev Med (São Paulo). 1992;71:108-13.

11. Silva LC, Vianna MR, Abrantes CP, et al. Liver morphology with emphasis on bile ducts changes and survival analysis in mice submitted to multiple Schistosoma mansoni infections and chemotherapy. Rev Inst Med Trop S Paulo. 1990;32: 328-37.

12. Silva-Neto WDeB, Cavarzan A, Herman P. Intraoperative evaluation of portal pressure and immediate results of surgical treatment of portal hypertension in schistosomotic patients submitted to esophagogastric devascularization with splenectomy. Arq Gastroenterol. 2004;41:150-4.

13. Camacho-Lobato L, Borges DR. Early liver dysfunction in schistosomiasis. J Hepatol. 1998;29: 233-40.

14. Mohamed-Ali Q, Elwali NE, Abdelhameed AA, et al. Susceptibility to periportal (Symmers) fibrosis in human Schistosoma mansoni infections: evidence that intensity and duration of infection, gender, and inherited factors are critical in disease progression. J Infect Dis. 1999;180:1298-306.

15. Sleigh AC, Mott KE, Hoff R, et al. Three-year prospective study of the evolution of Manson's schistosomiasis in north-east Brazil. Lancet. 1985;2:63-6.

16. Gryseels B, Polderman AM, Engels D. Experiences with the control of schistosomiasis mansoni in two foci in central Africa. Mem Inst Oswaldo Cruz. 1992;87 Suppl 4:187-94.

17. Brant PE, Kopke-Aguiar L, Shigueoka DC, et al. Anicteric cholangiopathy in schistosomiasis patients. Acta Trop. 2008;108:218-21.

18. Szejnfeld J. Comparação da colangiopancreatografia por ressonância magnética (CPRM) e por endoscopia retrógrada (CPER) em pacientes com suspeita de doenças biliares ou pancreáticas [tese de livre-docência]. São Paulo: Universidade Federal de São Paulo; 1999.

19. Fulcher AS. Magnetic resonance cholangiopan- creatography: is it becoming the study of choice for evaluating obstructive jaundice? J Clin Gastroenterol. 2004;38:839-40.

20. Fulcher AS, Turner MA. MR cholangiopancreatography. Radiol Clin North Am. 2002;40: 1363-76.

21. Bezerra AS, D'Ippolito G, Caldana RP, et al Chronic hepatosplenic schistosomiasis mansoni: magnetic resonance imaging and magnetic resonance angiography findings. Acta Radiol. 2007; 48:125-34.

22. Bezerra AS, D'Ippolito G, Caldana RP, et al. Avaliação hepática e esplênica por ressonância magnética em pacientes portadores de esquistossomose mansônica crônica. Radiol Bras. 2004;37:313-21.

23. Oliveira L, Andrade ZA. Significance of bile-duct changes in schistosomiasis. Rev Soc Bras Med Trop. 2005;38:464-8.

24. Schmid M, Pirovino M, Altorfer J, et al. Acute hepatitis non-A, non-B; are there any specific light microscopic features? Liver. 1982;2:61-7.

25. Ganc AJ. As alterações do sistema bilífero intrahepático: correlação anátomo-radiológica [tese de doutorado]. São Paulo: Escola Paulista de Medicina; 1974.

26. Ribeiro PJ, Narciso JL, de Toledo CF, et al. Gamma-glutamyltransferase decreases in patients with the chronic form of schistosomiasis mansoni treated with ursodeoxycholic acid. J Clin Pathol. 2005;58:783-4.

27. Martins RD, Borges DR. Ethanol challenge in non-alcoholic patients with schistosomiasis. J Clin Pathol. 1993;46:250-3.

28. Sakai Y, Tsuyuguchi T, Tsuchiya S, et al. Diagnostic value of MRCP and indications for ERCP. Hepatogastroenterology. 2007;54:2212-5.

29. Zajaczek JE, Keberle M. Value of radiological methods in the diagnosis of biliary diseases. Radiologe. 2005;45:976-8, 980-6.

30. Merkle EM, Haugan PA, Thomas J, et al. 3.0versus 1.5-T MR cholangiography: a pilot study. AJR Am J Roentgenol. 2006;186:516-21. 